\title{
ANALISIS PENDEKATAN MALCOLM BALDRIGE CRITERIA FOR PERFORMANCE EXCELLENCE (MBCfPE) TERHADAP KINERJA DI PT. KINENTA INDONESIA
}

\author{
Edi Susanto ${ }^{1}$ \\ ${ }^{1}$ Jurusan Teknik Industri, Fakultas Teknologi Industri, Institut Teknologi Nasional (Itenas) Bandung \\ Jl. PKH. Hasan Mustapa No. 23 Bandung 40124, Indonesia \\ Email : susanto.edi19@gmail.com
}

\begin{abstract}
The purpose of this research is to implement a self-assessment through a survey on the overaall performance measurement approuach Malcolm Baldrige Kriteria for Performance Excellent namely on seven criteria : leadership, strategi planning, customer fokus, measurement, analysis, and knowledge management, workforce focus, operation fokus and results to determine the level of performance in PT. Kinenta Indonesia. The research data was obtained from interviews, observations, questionnaires and literature. Then analyzed with the provisions of the assessment criteria MBCfPE. Thus obtained from the survey results MBCfPE with total points 784 points. Then in accordance with the scores level at posisu MBCfPE PT. Kinenta Indonesia performance Benchmark Leader with Excellent category.
\end{abstract}

Keywords: Performance, Overall Performance Measurement, MBCfPE

\section{Pendahuluan}

\subsection{Latar Belakang Masalah}

Didalam dunia industri, persaingan antara suatu perusahaan dengan perusahaan lain semakin kompetitif. Berkembangnya persaingan saat ini membuat perusahaan harus mampu mempertahankan kualitasnya maka diperlukan pengukuran kinerja. Pentingnya pengukuran kinerja pada suatu perusahaan untuk dapat mengetahui kekuatan dan kelemahan.

PT. Kinenta Indonesia merupakan perusahaan yang bergerak di bidang manufaktur (spare part otomotif), yang memproduksi produk Wiring Harnest. Bertambahnya perusahaan-perusahaan manufaktur sejenis di indonesia mengharuskan PT. Kinenta Indonesia untuk meningkatkan performansi dan kinerja perusahaannya dalam meningkatkan kualitas produk di Indonesia. Karena itu dibutuhkan pengukuran performansi kinerja secara keseluruhan agar PT. Kinenta Indonesia dapat mengetahui kekuatan dan kelemahan yang dimiliki perusahaan untuk mampu melakukan persaingan dan kemajuan perusahaan dimasa mendatang.

Saat ini PT. Kinenta Indonesia sudah melakukan pengukuran kualitas namun belum melakukan pengukuran kinerja secara keseluruhan, maka diperlukan metode Malcolm Baldrige Criteria for Performance Excellence (MBCfPE). MBCfPE merupakan salah satu metode untuk meningkatkan kinerja perusahaan secara keseluruhan dan terus menerus. MBCfPE memiliki tujuh kriteria yaitu kepimimpinan, perencanaan strategis, fokus pelanggan dan pasar, ukuran analisis dan manajemen pengetahuan, fokus kepada tenaga kerja, fokus kepada operasi dan hasil kinerja.

\subsection{Rumusan Masalah}

Berdasarkan latar belakang masalah yang sudah didapatkan, rumusan masalah yang dapat diangkat menjadi dasar penelitian adalah bagaimana level kinerja PT. Kinenta Indonesia ditinjau dari penerapan Malcolm Baldrige Criteria for Performance Excellence?

\subsection{Tujuan Penelitian}

Tujuan yang ingin di capai dalam penelitian ini yaitu :

1. Mengetahui level kinerja PT. Kinenta Indonesia berdasarkan kriteria Malcolm Baldrige Criteria for Performance Excellence.

2. Bahan usulan mengetahui sejauh mana peran PT. Kinenta Indonesia agar berdaya saing tinggi.

\section{Landasan Teori}

\subsection{Kinerja}

Menurut Mulyadi (2001:337) "Kinerja adalah keberhasilan personil, tim, atau unit organisasi dalam mewujudkan sasaran strategik yang telah ditetapkan sebelumnya dengan perilaku yang diharapkan.”. Kinerja perusahaan merupakan sesuatu yang dihasilkan oleh suatu perusahaan dalam periode tertentu dengan mengacu pada standar yang ditetapkan. 
Menurut Stout (1993: 33) yang dikutip dari LAN dan BPKP (2000) mengatakan bahwa pengukuran kinerja merupakan suatu proses mencatat dan mengukur pencapaian pelaksanaan kegiatan dalam arah pencapaian misi melalui hasil yang ditampilkan berupa produk, jasa, ataupun suatu proses.

Manfaat sistem pengukuran kinerja adalah (Mulyadi \& Setyawan, 1999:212-225) :

1. Menelusuri kinerja terhadap harapan pelanggannya dan membuat seluruh personil terlibat dalam upaya pemberi kepuasan kepada pelanggan.

2. Memotivasi pegawai untuk melakukan pelayanan sebagai bagian dari mata-rantai pelanggan dan pemasok internal. Mengidentifikasi berbagai pemborosan sekaligus mendorong upaya-upaya pengurangan terhadap pemborosan tersebut.

3. Membuat suatu tujuan strategi yang masanya masih kabur menjadi lebih kongkrit sehingga mempercepat proses pembelajaran perusahaan.

\subsection{Malcolm Baldrige Criteria for Performance Excellence \\ MBCfPE merupakan salah satu alat yang} dapat digunakan untuk mendiagnose dan mengevaluasi kinerja organisasi atau unit-unit kerja baik yang berorientasi profit atau non-profit secara keseluruhan dan terus-menerus. Terdapat sebelas tata nilai dan konsep inti yang membangun kriteria bisnis MBCfPE sebagai berikut (Vincent Gaspersz 2011;205) : Kepemimpinan visioner, keunggulan yang dikendalikan pelanggan, pembelajaran organisasi dan pribadi, menghargai karyawan dan mitra kerja, ketangkasan, berfokus masa depan, mengelola untuk inovasi, manajemen berdasarkan fakta, tanggung jawab social, berfokus pada hasilhasil dan penciptaan nilai, perspektif sistem.

Berikut merupakan gambar kerangka kategori MBCfPE yang dapat dilihat pada Gambar 1.

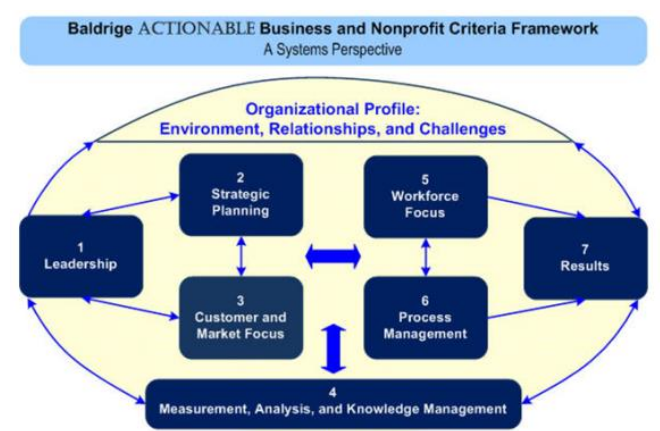

Gambar 1. Kerangka Kategori MBCfPE
Kriteria MBCfPE memiliki 7 kategori berdasarkan literatur “ Indonesian Quality Award Fundation “.Penyajian MBCfPE yang paling mutakhir adalah kriteria tahun 2011 - 2012 yakni: 1.Kepemimpinan, 2. Perencanaan Strategis, 3. Fokus Kepada Pelangggan dan Pasar, 4. Ukuran, Analisa dan Manajemen Pengetahuan, 5. Fokus Kepada Tenaga Kerja, 6. Fokus Kepada Proses dan 7. Hasil Bisnis.

\section{Metode Penelitian}

Metode penelitian merupakan langkahlangkah yang akan dilakukan dalam penelitian untuk mencapai tujuan yang diharapkan. Diagram alir penelitian ini merupakan gambar yang menjelaskan mengenai langkah-langkah penyelesaian penelitian ini yang terdiri dari latar belakang masalah, perumusan masalah, perumusan masalah, penentuan tujuan dan manfaat, landasan teori, pengumpulan data, pengolahan data, uji validitas, uji reliabilitas, analisis data, dan kesimpulan dan saran. Metode penelitian dapat dilihat pada Gambar 2.

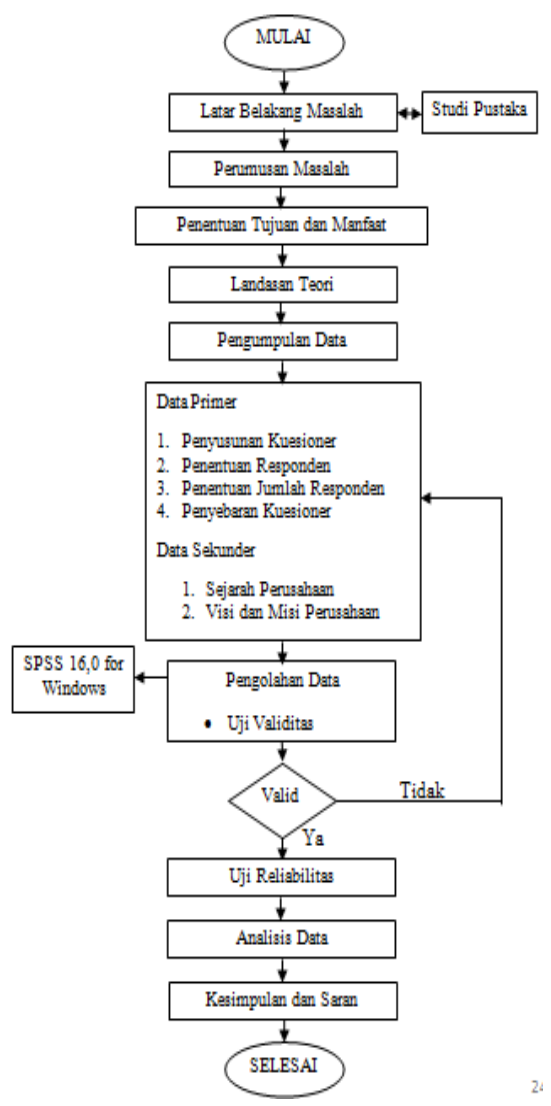

Gambar 2. Diagram Metodologi

\section{Hasil Penelitian dan Pembahasan}

4.1. Pengumpulan Data

Pengumpulan data diperoleh dari pengamatan, wawancara dan penyebaran kuisioner (dengan sample yg di ambil 63 responden dari 167 responden,dengan menggunakan rumus solvin). Data didapatkan dari karyawan PT. Kinenta Indonesia yaitu : staf, supervisior, dep.head, dan 
manajer. Data-data yang diperoleh didapatkan dari jawaban pertanyaan-pertanyaan dari pertanyaan masing-masing kriteria MBCfPE.

\subsection{Pengolahan Data}

Pengolahan data merupakan tahap selanjutnya. Tahapan pengolahan data terdiri dari karakteristik responden PT. Kinenta Indonesia, uji validitas, uji reliabilitas, analisis statistik deskriptif, scoring dan rekapitulasi scoring untuk seluruh kategori.

\subsubsection{Karakteristik Responden PT. Kinenta Indonesia}

Tabel 4.1. Karakteristik Responden Berdasarkan Usia

\begin{tabular}{|c|c|c|}
\hline Usia (Tahun) & Jumlah (Orang) & \% \\
\hline $18-20$ & 5 & $8 \%$ \\
\hline $20-30$ & 37 & $59 \%$ \\
\hline $31-40$ & 19 & $30 \%$ \\
\hline $41-50$ & 2 & $3 \%$ \\
\hline Total & $\mathbf{6 3}$ & $\mathbf{1 0 0} \%$ \\
\hline
\end{tabular}

Sumber : Hasil Penelitian, 2016 (Data diolah)

Pada tabel 4.1 usia responden yang paling dominan antara usia 20-30 tahun dengan jumlah 37 orang dengan presentase (59\%).

Tabel 4.2. Karakteristik Responden Berdasarkan Jenis Kelamin

\begin{tabular}{|c|c|c|}
\hline Jenis Kelamin & Jumlah (Orang) & \% \\
\hline Perempuan & 39 & $62 \%$ \\
\hline Laki-Laki & 24 & $38 \%$ \\
\hline Jumlah & $\mathbf{6 3}$ & $\mathbf{1 0 0} \%$ \\
\hline
\end{tabular}

Sumber : Hasil Penelitian, 2016 (Data diolah)

Pada tabel 4.2 menunjukan bahwa jenis kelamin responden perempuan lebih banyak dari pada laki-laki dengan jumlah 39 orang (62\%).

Tabel 4.3. Karakteristik Responden

Berdasarkan Pendidikan Terakhir

\begin{tabular}{|c|c|c|}
\hline $\begin{array}{c}\text { Pendidikan } \\
\text { Terakhir }\end{array}$ & Jumlah (Orang) & \% \\
\hline SMA/SMK & 42 & $67 \%$ \\
\hline Strata 1 & 20 & $32 \%$ \\
\hline Strata 2 & 1 & $1 \%$ \\
\hline Total & $\mathbf{6 3}$ & $\mathbf{1 0 0} \%$ \\
\hline
\end{tabular}

Sumber : Hasil Penelitian, 2016 (Data diolah)

Pada tabel 4.3 dapat disimpulkan bahwa pada umumnya bagian staff dan staff up PT. Kinenta Indonesia pendidikan terakhir SMA/SMK dan $\mathrm{S} 1$, adapun yang tamatan $\mathrm{S} 2$.

Tabel 4.4 Karakteristik Responden Berdasarkan Lama Kerja

\begin{tabular}{|c|c|c|}
\hline $\begin{array}{c}\text { Lama Masa } \\
\text { Kerja }\end{array}$ & Jumlah (Orang) & \% \\
\hline 1-5 Tahun & 43 & $68 \%$ \\
\hline 6-10 Tahun & 12 & $19 \%$ \\
\hline 11-15 Tahun & 5 & $8 \%$ \\
\hline 16-20 Tahun & 3 & $5 \%$ \\
\hline Total & $\mathbf{6 3}$ & $\mathbf{1 0 0} \%$ \\
\hline
\end{tabular}

Sumber : Hasil Penelitian, 2016 (Data diolah)
Pada tabel 4.4 menunjukan bahwa responden yang menjadi karyawan dari 1 sampai 5 tahun adalah 43 orang dengan presentase $(68 \%)$.

\subsubsection{Uji Validitas}

Uji validitas digunakan untuk mengukur sah atau valid tidaknya suatu kuesioner. Uji validitas dilakukan dengan membandingkan nilai $\mathrm{r}$ hitung dengan $\mathrm{r}$ tabel untuk tingkat signifikansi 5\% dari degree of freedom $(d f)=n-2,(63-2=61)$. Sehingga di peroleh $\mathrm{r}$ kritis/tabel nya $=0,248$ dan dinyatakan valid apabila $\mathrm{r}$ hitung $>\mathrm{r}$ tabel. (Imam Ghozali,2013:53).

Tabel 4.5 Hasil Uji Validitas

\begin{tabular}{|c|c|c|c|}
\hline No & Variabel & r hitung & $\mathbf{r}$ tabel \\
\hline 1 & Kepemimpinan & 0,564 & 0,248 \\
\hline 2 & $\begin{array}{c}\text { Perencanaan } \\
\text { Strategis }\end{array}$ & 0,572 & 0,248 \\
\hline 3 & $\begin{array}{c}\text { Fokus Kepada } \\
\text { Pelanggan dan } \\
\text { Pasar }\end{array}$ & 0,608 & 0,248 \\
\hline 5 & $\begin{array}{c}\text { Ukuran, Analisa } \\
\text { dan Manajemen } \\
\text { Pengetahuan }\end{array}$ & 0,497 & 0,248 \\
\hline 6 & $\begin{array}{c}\text { Fokus Kepada } \\
\text { Tenaga Kerja }\end{array}$ & 0,603 & 0,248 \\
\hline 7 & Fokus Kepada & 0,545 & 0,248 \\
\hline
\end{tabular}

Sumber : Hasil Penelitian, 2016 (Data diolah)

Berdasarkan Tabel 4.5 dapat dilihat bahwa hasil pengujian instrumen semua variabel kriteria MBCfPE valid karena nilai $r$ hitung diatas nilai $r$ kritis.

\subsubsection{Uji Reliabilitas}

Reliabilitas adalah alat untuk mengukur suatu kuesioner yang merupakan indikator dari variabel atau konstruk. Suatu konstruk atau variabel dikatakan reliabel jika memberikan nilai Cronbach Alpha > 0,7. (Imam Ghozali,2013:48).

Tabel 4.6 Hasil Uji Reliabilitas

\begin{tabular}{|c|c|c|c|}
\hline No & Variabel & $\begin{array}{c}\text { Cronbach } \\
\text { Alpha } \\
\text { Hitung }\end{array}$ & $\begin{array}{c}\text { Cronbach } \\
\text { Alpha }\end{array}$ \\
\hline 1 & Kepemimpinan & 0,846 & 0,7 \\
\hline 2 & $\begin{array}{c}\text { Perencanaan } \\
\text { Strategis }\end{array}$ & 0,807 & 0,7 \\
\hline 3 & $\begin{array}{c}\text { Fokus Kepada } \\
\text { Pelanggan dan } \\
\text { Pasar }\end{array}$ & 0,868 & 0,7 \\
\hline 5 & $\begin{array}{c}\text { Anuran, } \\
\text { Manajemen } \\
\text { Pengetahuan }\end{array}$ & 0,772 & 0,7 \\
\hline 5 & $\begin{array}{c}\text { Fokus Kepada } \\
\text { Tenaga Kerja }\end{array}$ & 0,844 & 0,7 \\
\hline 7 & $\begin{array}{c}\text { Fokus Kepada } \\
\text { Operasi }\end{array}$ & 0,82 & 0,7 \\
\hline Kinerja & 0,848 & 0,7 \\
\hline
\end{tabular}

Sumber : Hasil Penelitian, 2016 (Data diolah) 
Berdasarkan tabel 4.6 hasil uji reliabilitas kinerja di semua variabel kriteria MBCfPE didapatkan nilai $\alpha>0,7$ sehingga dapat dikatakan bahwa hasil kuisioner semua variabel telah reliabel, sehingga layak dipergunakan dalam penelitian.

Tabel 7. Penjelasan Responden Variabel Kepemimpinan

\begin{tabular}{|l|c|c|c|c|c|}
\hline \multirow{2}{*}{ Indikator } & STS & S & TS & SS & Total \\
\cline { 2 - 5 } & Jumlah & Jumlah & Jumlah & Jumlah & \\
\hline $\begin{array}{l}\text { Visi, Misi } \\
\text { dan Nilai- } \\
\text { nilai }\end{array}$ & 0 & 0 & 49 & 14 & 63 \\
\hline $\begin{array}{l}\text { Komunikasi } \\
\text { dan kinerja } \\
\text { organisasi }\end{array}$ & 0 & 1 & 49 & 13 & 63 \\
\cline { 2 - 5 } & 0 & 2 & 44 & 17 & 63 \\
\hline $\begin{array}{l}\text { Tata Kelola } \\
\text { Organisasi }\end{array}$ & 0 & 3 & 47 & 13 & 63 \\
\hline $\begin{array}{l}\text { Perilaku } \\
\text { etis dan } \\
\text { patuh } \\
\text { hukum }\end{array}$ & 0 & 3 & 38 & 22 & 63 \\
\hline $\begin{array}{l}\text { Tanggung } \\
\text { jawab } \\
\text { sosial dan } \\
\text { mendukung } \\
\text { komunitas } \\
\text { kunci }\end{array}$ & 0 & 7 & 31 & 21 & 63 \\
\hline
\end{tabular}

Sumber : Hasil Penelitian, 2016 (Data diolah)

Tabel 8. Penjelasan Responden Variabel Perencanaan Strategis

\begin{tabular}{|c|c|c|c|c|c|}
\hline \multirow{2}{*}{ Indikator } & STS & S & TS & SS & \multirow{2}{*}{ Total } \\
\cline { 2 - 5 } & Indikator & STS & S & TS & \\
\hline $\begin{array}{c}\text { Proses } \\
\text { pengembangan } \\
\text { strategi }\end{array}$ & 0 & 7 & 48 & 8 & 63 \\
\cline { 2 - 6 } & 0 & 7 & 42 & 14 & 63 \\
\hline $\begin{array}{c}\text { Sasaran } \\
\text { strategi }\end{array}$ & 0 & 8 & 47 & 8 & 63 \\
\hline $\begin{array}{c}\text { Pengembangan } \\
\text { dan penjabaran } \\
\text { rencana kerja }\end{array}$ & 0 & 9 & 51 & 3 & 63 \\
\hline Proyeksi kerja & 0 & 16 & 40 & 7 & 63 \\
\cline { 2 - 6 } & 0 & 2 & 36 & 25 & 63 \\
\hline
\end{tabular}

Sumber : Hasil Penelitian, 2016 (Data diolah)

Tabel 9. Penjelasan Responden Variabel Fokus

\begin{tabular}{|c|c|c|c|c|c|}
\hline \multirow{2}{*}{ Indikator } & STS & TS & S & SS & \multirow{2}{*}{ Total } \\
\cline { 2 - 5 } & Jml & Jml & Jml & Jml & \\
\hline Mendengarkan & 0 & 8 & 45 & 10 & 63 \\
\cline { 2 - 5 } pelanggan & 1 & 5 & 47 & 10 & 63 \\
\hline $\begin{array}{c}\text { Memperoleh } \\
\text { informasi } \\
\text { kepuasan } \\
\text { pelanggan }\end{array}$ & 0 & 4 & 41 & 18 & 63 \\
\cline { 2 - 5 } & 0 & 5 & 38 & 20 & 63 \\
\hline $\begin{array}{c}\text { Menganalisa } \\
\text { dan mendata } \\
\text { pelanggan }\end{array}$ & 0 & 6 & 43 & 14 & 63 \\
\cline { 2 - 5 } & 0 & 1 & 46 & 16 & 63 \\
\hline $\begin{array}{c}\text { Penawaran } \\
\text { produk dan } \\
\text { mendukung } \\
\text { pelanggan }\end{array}$ & 0 & 1 & 39 & 23 & 63 \\
\cline { 2 - 5 } & 0 & 2 & 41 & 20 & 63 \\
\hline $\begin{array}{c}\text { Membangun } \\
\text { budaya fokus } \\
\text { kepada }\end{array}$ & 0 & 18 & & \\
\hline $\begin{array}{c}\text { pelanggan } \\
\text { Melang }\end{array}$ & & & & & \\
\hline
\end{tabular}

Tabel 10. Penjelasan Responden Variabel Ukuran, Analisa dan Manajemen Pengetahuan

\begin{tabular}{|c|c|c|c|c|c|}
\hline \multirow{3}{*}{ Indikator } & & & & & \multirow{3}{*}{ Total } \\
\hline & STS & TS & $\mathbf{S}$ & SS & \\
\hline & Jml & $\mathbf{J m l}$ & Jml & $\mathbf{J m l}$ & \\
\hline \multirow{2}{*}{$\begin{array}{l}\text { Ukuran } \\
\text { kinerja }\end{array}$} & 0 & 2 & 47 & 14 & 63 \\
\hline & 0 & 10 & 47 & 6 & 63 \\
\hline $\begin{array}{c}\text { Analisa dan } \\
\text { review } \\
\text { kinerja }\end{array}$ & 0 & 2 & 51 & 10 & 63 \\
\hline $\begin{array}{l}\text { Perbaikan } \\
\text { kinerja }\end{array}$ & 0 & 2 & 45 & 16 & 63 \\
\hline \multirow{2}{*}{$\begin{array}{c}\text { Data, } \\
\text { informasi } \\
\text { dan } \\
\text { pengetahuan } \\
\text { organisasi }\end{array}$} & 0 & 4 & 44 & 15 & 63 \\
\hline & 0 & 10 & 37 & 16 & 63 \\
\hline $\begin{array}{l}\text { Pengelolaan } \\
\text { sumber } \\
\text { informasi } \\
\text { dan } \\
\text { teknologi } \\
\end{array}$ & 0 & 6 & 43 & 14 & 63 \\
\hline
\end{tabular}

Sumber : Hasil Penelitian, 2016 (Data diolah)

Tabel 11. Penjelasan Responden Variabel Fokus Kepada Tenaga Kerja

\begin{tabular}{|c|c|c|c|c|c|}
\hline \multirow{2}{*}{ Indikator } & STS & TS & S & SS & \multirow{2}{*}{ Total } \\
\cline { 2 - 6 } & Jml & Jml & Jml & Jml & \\
\hline $\begin{array}{c}\text { Kapabilitas } \\
\text { dan kapasitas } \\
\text { tenaga kerja }\end{array}$ & 0 & 2 & 43 & 18 & 63 \\
\cline { 2 - 6 } & 0 & 7 & 39 & 17 & 63 \\
\hline $\begin{array}{c}\text { Lingkungan } \\
\text { tenaga kerja }\end{array}$ & 0 & 7 & 42 & 14 & 63 \\
\hline $\begin{array}{c}\text { Pemerkayaan } \\
\text { tenaga kerja }\end{array}$ & 0 & 2 & 41 & 20 & 63 \\
\hline $\begin{array}{c}\text { Pengembangan } \\
\text { tenaga kerja } \\
\text { dan pemimpin }\end{array}$ & 0 & 4 & 47 & 12 & 63 \\
\hline $\begin{array}{c}\text { Penilaian } \\
\text { terhadap }\end{array}$ & 0 & 3 & 48 & 12 & 63 \\
$\begin{array}{c}\text { penanganan } \\
\text { tenaga kerja }\end{array}$ & & & & & \\
\hline
\end{tabular}

Sumber : Hasil Penelitian, 2016 (Data diolah)

Tabel 12. Penjelasan Responden Variabel Fokus Kepada Operasi

\begin{tabular}{|l|c|c|c|c|c|}
\hline \multirow{2}{*}{ Indikator } & STS & TS & S & SS & \multirow{2}{*}{ Totsl } \\
\cline { 2 - 5 } & Jml & Jml & Jml & Jml & \\
\hline $\begin{array}{l}\text { Desain sistem } \\
\text { kerja }\end{array}$ & 0 & 16 & 46 & 1 & 63 \\
\cline { 2 - 5 } $\begin{array}{l}\text { Proses kerja } \\
\text { kunci }\end{array}$ & 1 & 2 & 47 & 13 & 63 \\
\hline $\begin{array}{l}\text { Kesiapan } \\
\text { sistem kerja } \\
\text { dalam keadaan } \\
\text { bencana/darurat }\end{array}$ & 0 & 5 & 44 & 14 & 63 \\
\hline $\begin{array}{l}\text { Desain proses } \\
\text { kerja }\end{array}$ & 0 & 1 & 52 & 10 & 63 \\
\cline { 2 - 5 } & 0 & 2 & 52 & 9 & 63 \\
\hline $\begin{array}{l}\text { Pengaturan } \\
\text { proses kerja }\end{array}$ & 0 & 1 & 47 & 15 & 63 \\
\hline $\begin{array}{l}\text { Perbaikan } \\
\text { proses kerja }\end{array}$ & 0 & 2 & 48 & 13 & 63 \\
\hline
\end{tabular}

Sumber : Hasil Penelitian, 2016 (Data diolah) 
Tabel 13. Penjelasan Responden Variabel Kinerja

\begin{tabular}{|c|c|c|c|c|c|}
\hline \multirow{2}{*}{ Indikator } & STS & TS & $\mathbf{S}$ & SS & \multirow{2}{*}{ Total } \\
\hline & $\mathbf{J m l}$ & $\mathbf{J m l}$ & $\mathbf{J m l}$ & Jml & \\
\hline \multirow{2}{*}{$\begin{array}{l}\text { Hasil kinerja } \\
\text { produk dan } \\
\text { proses }\end{array}$} & 0 & 1 & 53 & 9 & 63 \\
\hline & 0 & 4 & 44 & 15 & 63 \\
\hline \multirow{2}{*}{$\begin{array}{c}\text { Hasil kinerja } \\
\text { fokus kepada } \\
\text { pelanggan }\end{array}$} & 0 & 4 & 49 & 10 & 63 \\
\hline & 0 & 1 & 48 & 14 & 63 \\
\hline \multirow{2}{*}{$\begin{array}{l}\text { Hasil kinerja } \\
\text { kepada tenaga } \\
\text { kerja }\end{array}$} & 0 & 5 & 40 & 18 & 63 \\
\hline & 0 & 6 & 46 & 11 & 63 \\
\hline \multirow{2}{*}{$\begin{array}{l}\text { Hasil kinerja } \\
\text { kepemimpinan } \\
\text { dan tata kelola }\end{array}$} & 0 & 12 & 43 & 8 & 63 \\
\hline & 0 & 2 & 50 & 11 & 63 \\
\hline \multirow{2}{*}{$\begin{array}{c}\text { Hasil kinerja } \\
\text { finansial dan } \\
\text { pasar }\end{array}$} & 1 & 3 & 51 & 8 & 63 \\
\hline & 1 & 4 & 51 & 7 & 63 \\
\hline
\end{tabular}

Sumber : Hasil Penelitian, 2016 (Data diolah)

\subsubsection{Scorcing Hasil MBCfPE}

Tabel 14. Poin Scorcing Hasil MBCfPE

\begin{tabular}{|c|c|c|c|c|}
\hline No & MBCfPE & $\begin{array}{l}\text { Total } \\
\text { Poin }\end{array}$ & $\begin{array}{l}\text { Skor } \\
\text { Poin }\end{array}$ & $\begin{array}{c}\% \\
\text { Total } \\
\text { Poin } \\
\end{array}$ \\
\hline 1 & Kepemimpinan & 120 & 96 & $80 \%$ \\
\hline 2 & $\begin{array}{l}\text { Perencanaan } \\
\text { Strategis }\end{array}$ & 85 & 65 & $77 \%$ \\
\hline 3 & $\begin{array}{l}\text { Fokus Kepada } \\
\text { Pelanggan dan } \\
\text { Pasar }\end{array}$ & 85 & 68 & $80 \%$ \\
\hline 4 & $\begin{array}{l}\text { Ukuran, } \\
\text { Analisa dan } \\
\text { Manajemen } \\
\text { Pengetahuan }\end{array}$ & 90 & 71 & $79 \%$ \\
\hline 5 & $\begin{array}{l}\text { Fokus Kepada } \\
\text { Tenaga Kerja }\end{array}$ & 85 & 68 & $80 \%$ \\
\hline 6 & $\begin{array}{l}\text { Fokus Kepada } \\
\text { Operasi }\end{array}$ & 85 & 66 & $78 \%$ \\
\hline 7 & Kinerja & 450 & 350 & $78 \%$ \\
\hline
\end{tabular}

Sumber : Hasil Penelitian, 2016 (Data diolah)

Dari jumlah total poin hasil survei Malcolm Baldrige Criteria for Performance Excellence di atas dengan jumlah $\mathbf{7 8 4}$ poin. Maka sesuai dengan level skor MBCfPE Kinerja PT. Kinenta Indonesia yaitu pada posisi Benchmark Leader dengan kategori Excellent.

Berdasarkan penelitian hasil penilaian kinerja maka dapat digambarkan posisi kinerja pada PT. Kinenta Indonesia dalam bentuk diagram kartesius berikut ini :

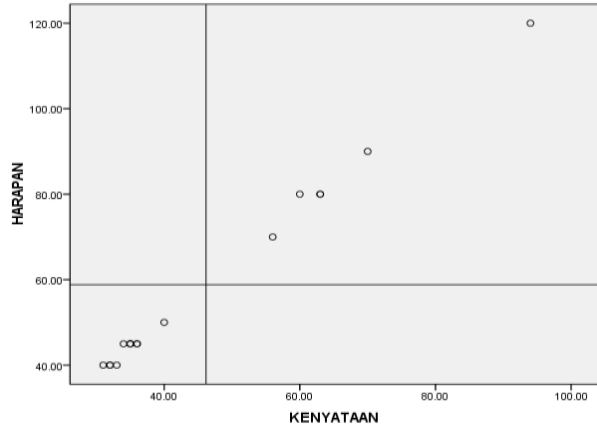

Gambar 4. Hasil Diagram Kartesius Poin MBCFPE

Hasil penilaian kinerja PT. Kinenta Indonesia berada pada kuadran B dan kuadran C yaitu menunjukan bahwa unsur-unsur kinerja pokok yang dianggap penting oleh karyawan telah dilaksanakan dengan baik dan dapat memuaskan karyawan, maka kini kewajiban dari perusahaan adalah mempertahankan kinerja.

\section{Kesimpulan dan Saran}

\subsection{Kesimpulan}

Berdasarkan dari hasil penelitian yang telah dilakukan dapat disimpulkan sebagai berikut:

1. Pencapaian kinerja PT. Kinenta Indonesia sesuai dengan level skor MBCfPE yaitu pada posisi Benchmark Leader dengan kategori Excellent.

2. Hasil penilaian kinerja PT. Kinenta Indonesia menunjukan bahwa unsur-unsur kinerja pokok yang dianggap penting oleh karyawan telah dilaksanakan dengan baik dan dap at memuaskan karyawan, maka kini kewajiban dari perusahaan adalah mempertahankan kinerja.

\subsection{Saran}

Berdasarkan tujuan penelitian ini yaitu untuk mengukur pencapaian kinerja PT. Kinenta Indonesia berdasarkan kriteria Malcolm Baldrige Criteria for Performance Excellence, saran yang dapat diajukan yaitu Benchmark Leader,perusahaan harus mempertahankan dan memantapkan posisinya dan diharapakan perusahaan bisa menuju ke level perusahaan kelas dunia dengan perbaikan yang dilakukan pada kategori dan indikaator yang masih perlu diperbaiki.

\section{DAFTAR PUSTAKA}

Hardiansyah. (2012). Analisis Pengaruhh Pendekatan Malcolm Baldrige Criteria For Performance Excellence Terhadap Kinerja PT. TRAKINDO UTAMA CABANG MEDAN. Tesis padaa program studi S-2 Ilmu Manajemen Universitas Sumatera Utara Medan.

Hary Sajiwo, M. (2012). Pengukuran Kinerja Perbankan Menggunakan Kriteria MBNQA (Studi Kasus Pada PT. Bank XYZ). Skripsi 
pada program studi S-1 Teknik Industri Universitas Sebelas Maret.

Imam Ghozali. 2016. Aplikasi Analisis Multivariate dengan Program SPSS Edisi 7. Semarang: Badan Penerbit Universitas Diponegoro.

Kuspijani, DR.Ir. Sudarso, I, MT. “ Pengukuran Kinerja Fakultas Teknik Universitas Bhayangkara Surabaya Dengan Menggunakan Kriteria Malcolm Baldrige “. Jurnal Institut Teknologi Sepuuh Nopember.

Nur Fitriani, L. Harsono, A. Arijanto, S. “ Pengukuran Performansi Berdasarkan MBCfPE Pada Kategori Perencanaan Strategis Serta Kategori Hasil Kinerja Keuangan Dan Pasar Di Yayasan X “ Jurnal online Institut Teknologi Nasional.
Naraswati, N. (2011). Pengaruh Penerapan Sistem Manajemen Kualitas dengan Kriteria MBNQA Terhadap Kinerja Bisnis (Studi Kasus Pada PT. Petrokimia Gresik). Skripsi pada program Ekonomi dan Bisnis Universitas Airlangga Surabaya.

Sugiyono. 2015. Statistika untuk Penelitian. Bandung: Alfabeta.

Vincent Gaspersz. 2011. Malcolm Baldrige Criteria For Performance Excellence. Vinchristo Publication. 